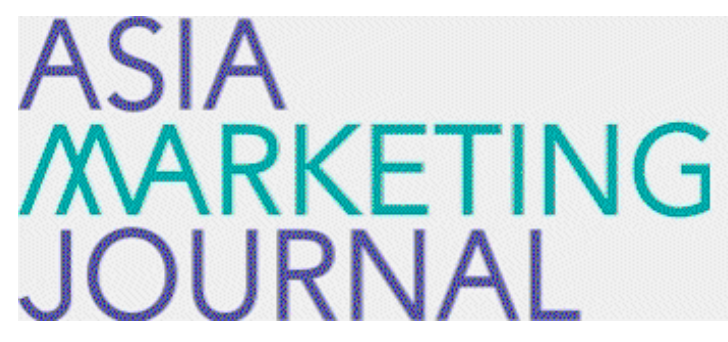

ASIA MARKETING JOURNAL

Volume 16 | Issue 2

Article 4

7-30-2014

\title{
Consumer Locus of Control as a Moderator of the Relationship between Mood and Consumers`'Likelihood to Purchase
}

\author{
Felix Septianto \\ Minghao Huang \\ Jaeseok Jeong
}

Follow this and additional works at: https://amj.kma.re.kr/journal

Part of the Marketing Commons

\section{Recommended Citation}

Septianto, Felix; Huang, Minghao; and Jeong, Jaeseok (2014) "Consumer Locus of Control as a Moderator of the Relationship between Mood and Consumers' Likelihood to Purchase," Asia Marketing Journal: Vol. 16 : Iss. 2 , Article 4.

Available at: https://doi.org/10.53728/2765-6500.1540

This Article is brought to you for free and open access by Asia Marketing Journal. It has been accepted for inclusion in Asia Marketing Journal by an authorized editor of Asia Marketing Journal. 


\title{
Consumer Locus of Control as a Moderator of the Relationship between Mood and Consumers' Likelihood to Purchase*
}

\author{
Felix Septianto** \\ Minghao Huang*** \\ Jaeseok Jeong****
}

\begin{abstract}
Although previous works have established that mood can considerably influence consumer behavior (Vohs et al. 2007), they provided inconsistent results (Cohen et al. 2008). In particular, previous works only examined the willingness of consumers to regulate their mood and implicitly assumed that consumers have the control to regulate their mood states. Thus, this research intends to fill the current gap in the extant literatures by investigating whether consumer locus of control (CLOC) can act as a moderator for mood effects on consumers' likelihood to purchase.

In an experiment, participants' CLOC was initially measured. Afterwards, they watched different video clips to induce different mood states. Finally, participants rated their likelihood to purchase after seeing an advertisement. The results suggest that, in the positive mood, CLOC tendencies do not impact consumers' likelihood to purchase. However, in the negative mood, internal CLOC consumers show a higher likelihood to purchase than external CLOC consumers. This phenomenon occurs because consumers with high internal CLOC tendencies have the motivation to regulate their negative mood.

These findings extend the extant literatures in four aspects. First, this paper shows that the CLOC tendencies could influence consumers' motivation to regulate their negative mood. Second, this research examines the moderating effect of CLOC in the relationship between mood and consumers' likelihood to purchase. Third, the results add further evidence regarding the role of negative mood in the self-regulation process. Finally, this research also shows that mood can unconsciously influence consumer behavior. This paper provides two managerial implications. First, marketers should consider the mood states and consumers' control tendencies in creating advertisements. Second, firms in retail or service business should aim to evoke a positive mood on consumers so that their CLOC tendencies would not influence their behaviors.
\end{abstract}

Key words: Mood Regulation, Consumer Locus of Control, Purchase Intention, Advertising

The authors acknowledge Ansley Burns for her support so that her students can participate in the research.

** Master's Candidate, Graduate School of Pan-Pacific International Studies, Kyung Hee University

(septianto.felix@gmail.com)

**** Assistant Professor of Management, College of International Studies, Kyung Hee University(mhuang@khu.ac.kr), Corresponding Author

***** Associate Professor of Marketing, Graduate School of Pan-Pacific International Studies, Kyung Hee University (profjeong@khu.ac.kr) 


\section{Introduction}

Prior works have established that mood can influence consumer decision-making process and behavior in diverse ways (Luomala and Laaksonen 2000; Vohs et al. 2007). For instance, when consumers experience negative mood (e.g., stress), there can be a substantial variability in their consumption (Leipämaa-Leskinen 2007; O'Connor et al. 2008). Some consumers may choose not to purchase a food product because they do not feel like having one (i.e. no desire to eat), while others may choose to purchase a food product because they think they would feel better after having one (i.e. desire to eat much).

Previous research has tried to explore the moderators of mood effects on consumer behavior, such as product attribute (Andrade 2005), consumer traits (Andrade 2005; Puccinelli et al. 2007; Smith and Petty 1995), consumer goal-orientation (Arnold and Reynolds 2009), and culture (Maier et al. 2012); however, these studies only examined the willingness of consumers to regulate their mood and simply assumed that consumers have the control to regulate their mood. However, there is a possibility that consumers feel they cannot regulate their mood (they have no control) although they are willing to regulate their mood. This "control" variable needs further consideration because this factor could significantly influence consumers' motivation to regulate their mood (Leotti et al. 2010).

This paper aims to investigate whether consumer locus of control (CLOC) could moderate mood effects on consumers' likelihood to purchase; specifically, this research proposes that: In the positive mood condition, CLOC tendencies would not influence consumers' likelihood to purchase; however, in the negative mood condition, higher (vs. lower) tendencies of internal CLOC would lead to higher (vs. lower) consumers' likelihood to purchase. This paper argues that this phenomenon occurs because consumers with higher internal tendencies have higher motivation to regulate their negative mood states.

This paper has several potential contributions. First, this paper examines the notion that consumers may (vs. may not) have the control to regulate their mood. Second, this study increases the understanding of how consumers' control tendencies can moderate mood effects on consumer behavior. Third, this paper adds evidence concerning the role of mood in selfregulation. Fourth, this research also further proves that mood can be processed in consumer judgment process through unconscious manner. In the subsequent sections, the theoretical background of this research is presented. Next, the methods and results of the experiment are explained. Finally, this paper discusses the theoretical and managerial implications, as well as avenues for future research. 


\section{Literature Review}

\subsection{Mood Effects on Consumer Judgment Process}

Mood is commonly defined as a particular affective state of an individual, while affect is generally used as the "umbrella" term for mood and emotion (Arnold and Reynolds 2009; Baas 2005). Because there is still no clear consensus concerning the specific definition of mood (Luomala and Laaksonen 2000), mood is grasped by contrasting it with emotion (Siemer 2001). This research defines mood as diffused, mild positive or negative affective state because diffuseness is considered to be the main distinction of mood compared to emotion (Baas 2005: Cohen and Areni 1991: Morris and Reilly 1987). As an illustration, consider negative mood and fear. Although both negative mood and fear are $\mathrm{ex}^{-}$ amples of negative affect, negative mood is somehow more diffused than fear because fear is also associated with uncertainty (Bok and Min 2013). However, although mood is considered to be milder than emotion (Cohen and Areni 1991), certain mood conditions (e.g., clinical depression) are more intense than emotion (Baas 2005).

The implications of mood on consumer judgment process have been widely studied (Luomala and Laaksonen 2000; Vohs et al. 2007). However, these studies can be collectively div- ided into two main groups: (1) studies on mood evaluation effect and (2) studies on mood regulation effect (Andrade 2005). Mood evaluation effect occurs when the current mood of consumers influences their perception, evaluation, and behavior. This effect is drawn upon the concept that mood prompts "informational impact" on individual judgment process (Gendolla 2000). This concept can be based on several theories, such as associative network model of memories (Bower 1981) or informational capacities of mood (Schwarz and Clore 1983). Based on these predictions, positive mood leads to more favorable consumers' responses, and negative mood leads to less favorable consumers' responses.

The manifestation of mood regulation effect is primarily built on basic hedonistic principle: People are motivated to approach pleasure and avoid pain (Higgins 1997). Consequently, consumers tend to behave in action in order to relieve their negative mood or to maintain their positive mood (Meloy 2000). For instance, consumers in a positive mood favor a product which promotes similar arousal level; in contrast, consumers in the negative mood favor a product which promotes opposite arousal level (Di Muro and Murray 2012). However, because previous studies offered inconsistent results (Cohen et al. 2008; Rusting 1998), the moderators between mood and consumer judgment process remain unclear. Moderating variables that have been suggested are product attribute 
(Andrade 2005), consumer traits (Andrade 2005: Puccinelli et al. 2007; Smith and Petty 1995), consumer goal-orientation (Arnold and Reynolds 2009), and culture (Maier et al. 2012).

Andrade (2005) proposed that some products possess a mood-lifting attribute; hence, these products would increase consumers' willingness to regulate their negative mood. Consumer traits can also moderate mood effects on consumer behavior. Further, Andrade (2005) showed that female consumers tend to view chocolate as a mood-lifting product; consequently, in the negative mood, female consumers (not male consumers) show high evaluation toward chocolate. Smith and Petty (1995) suggested that people with high Self-Esteem, a self-concept element that evaluates how favorable an individual views oneself (Baumeister 1998), tend to recall their positive memories to regulate their negative mood.

Self-Monitoring trait (SM), the tendency to monitor oneself and conform to social norms (Gangestad and Snyder 2000), can also moderate mood effects on consumer behavior. Research of Puccinelli et al. (2007) showed that high $\mathrm{SM}$ consumers tend to regulate their mood to meet the common social expectations; thus, high SM consumers show mood regulation effect. However, because low SM consumers do not tend to behave in order to fit in others' $\mathrm{ex}^{-}$ pectations, they show mood evaluation effect. Arnold and Reynolds (2009) also demonstrated that consumer goal-orientation (Higgins 1997) could influence people tendencies to regulate their mood. They proposed that people with high promotion focus in the negative mood are likely to regulate their negative mood because negative mood is not consistent with their promotion focus toward the achievement of a positive outcome.

Maier et al. (2012) supported the findings of Andrade (2005) and further proposed that cultural aspect (i.e. Collectivism vs. Individualism) can influence consumer perceptions toward mood-lifting attribute of a product: People of collectivistic countries (e.g., Turkey) tend to adjust themselves to their in-group (Luomala et al. 2004); therefore, they would show mood regulation effect. On the other hand, because people from individualistic countries (e.g., Germany) are not used to adjusting themselves to their environment, they would show mood evaluation effect (Maier et al. 2012).

\subsection{The Moderating Role of Consumer Locus of Control}

Prior works on mood effects were limited by focusing only on the willingness of consumers to regulate their mood states and by assuming that consumers are in control to regulate their mood. It is important to consider that consumers may be willing to regulate their mood; however, they cannot regulate their mood because they feel they have no control over it. In the context of purchase behavior, this research examines the consumer locus of control (CLOC) 
as a variable which can evaluate the degree to which the consumers perceive the ability to control. Further, CLOC here describes how consumers are perceived themselves as responsible agents of satisfactory or unsatisfactory outcome on their purchase behaviors (Busseri et al. 1998).

Internal CLOC individuals believe that the outcome of purchase behavior is contingent on their self-behavior, while external CLOC individuals believe that the outcome of purchase behavior is contingent on uncontrollable factors (e.g., others' power, luck, or the environment). Further, higher internal tendencies are associated with higher motivation to regulate negative mood states (Leotti et al. 2010). Consequently, because consumers with higher internal CLOC tendencies believe that they have the control concerning the outcome of a purchase behavior, they would naturally show more motivation to regulate their negative mood using a purchase behavior.

Mood regulation effect emerges when consumers try to maintain their positive mood and relieve their negative mood. Two factors are crucial in the manifestation of mood regulation effect (Gendolla 2000): (1) the extent to which a behavior leads to positive mood's maximization and negative mood's minimization (instrumentality); and (2) consumer motivation. Because previous research has established how consumers tend to regulate their mood through their consumption (Garg et al. 2007; Kemp and Kopp 2011), a purchase behavior has a high instrumentality for consumers to regulate their mood.

People's motivation to regulate their mood could increase when they experience negative mood because negative mood indicates a negative outcome (Carver and Scheier 1998; Labroo and Rucker 2010). However, this motivation depends on the degree of control people perceive to change their current state (i.e. 1ocus of control). This control is crucial because when people believe that they possess the control, they are motivated to self-regulate and make a better response (Baumeister 1998; Leotti et al. 2010). However, when people do not believe that they possess the control, it would lead to a depressed condition in which they have no motivation (Seligman 1975); hence, this situation can prevent them to behave in the desired action and outcome (Baumeister 1998; Leotti et al. 2010).

In the negative mood condition, because internal CLOC individuals believe that the result of purchase behavior is contingent on their self-behavior, they would be motivated to approach a positive outcome (i.e. feeling better) by purchasing a product; thus, they would show a high likelihood to purchase. On the other hand, because external CLOC individuals believe that the result of purchase behavior is contingent on other external factors, they would not be motivated to change their current state; thus, they would show a low likelihood to purchase. Further, in the positive mood con- 
dition, consumers' likelihood to purchase would not be influenced by their CLOC tendencies because their current evaluation and motivation to regulate would result in favorable responses. Formally, the hypotheses of this research can be stated as follows.

H1: In the positive mood condition, CLOC tendencies would not influence consumers' likelihood to purchase.

H2: In the negative mood condition, higher (vs. lower) tendencies of internal CLOC would lead to higher (vs. lower) consumers' likelihood to purchase.

\section{Methodology}

\subsection{Participants, Procedure, and Materials}

Data for the experiment were collected from one hundred and three undergraduate students (54 men and 49 women) from a private university in South Korea. The experiment was conducted as part of their English language courses (i.e. to rate how well an English presentation was performed). Before the experiment began, participants were told that there will be three (ostensibly) separate studies. First, participants were asked to complete CLOC questionnaires (adapted from Busseri et al.
1998); this questionnaire consisted of 14 items (6 internal CLOC items and 8 external CLOC items) with a 9-points scale. Higher score in this questionnaire means the more external tendency an individual is; thus, score of the internal items was reversed during the calculation process. Based on a pre-test ( $\alpha=$ .662), three items were removed from the questionnaire, yielding a total of 11 items in the questionnaire ( $\alpha=.756)$.

After the first study, they were randomly divided into two mood groups (i.e. positive and negative mood), and each group watched different video clip to induce different mood states; mood manipulation procedure is further described in the next section. Finally, participants rated how much the likelihood they would buy the product advertised (i.e. Fruit Dessert) in a 9-points scale (anchored from 1 $=$ very unlikely to $9=$ very likely). Pre-test and short interview were conducted before the main experiment to set the appropriate product price. Pre-test results confirmed that the product is desirable and the price is reasonable. This advertisement describes a fruit bowl made of orange skin. Inside this fruit bowl, there different kinds of fruits. This ad can be seen in the appendix section (adapted from Litoral 2013). After the experiment, some participants had a short interview, and then, they were debriefed and thanked. 


\subsection{Mood Manipulation}

Mood manipulation was induced using video clips with music background because prior studies have showed that they are effective to induce affective state of participants (Andrade 2005: Di Muro and Murray 2012; Hwang et al. 2012). The clip from Schindler's List was used for negative mood condition, and the clip from Toy Story 3 was used for positive mood condition. These clips were chosen because the pre-test results confirmed the effectiveness of these clips. In the mood manipulation questionnaire (adapted from Arnold and Reynolds 2009), participants were asked to rate their feelings in a 9-points scale, regarding positive valence (happy, pleasant, cheerful), negative valence (sad, depressed, discomfort), and additional fillers (bored, interested, focused) to mask the experiment's focus on positive and negative mood. In the calculation process, filler items were removed from the calculation; then, three positive-affect items ( $\alpha=.838)$ and three negative-affect items $(\alpha=.805)$ were collapsed to form positive-affect and negative-affect index.

\section{Results}

Results show that mood manipulation procedure worked as expected to induce different mood states (i.e. positive and negative mood states) on the participants. Participants in the positive mood condition felt more positive mood than participants in the negative mood condition $\left(M_{\text {positive vs, negative }}=6.32\right.$ vs. $1.13 ; S D$ positive vs, negative $=1.45$ vs. $.34 ; t(55)=24.96, p$ $<.001)$; conversely, participants in the negative mood condition felt more negative mood than participants in the positive mood condition $\left(M_{\text {positive vs. negative }}=1.13\right.$ vs. $5.97 ; S D$ positive vs. negative $=.28$ vs. $1.58 ; t(54)=-21.717, p<.001)$.

Table 1 presents the summary statistics of the data collected. From this data, preliminary analysis was conducted. CLOC scores were divided into two tendencies based on median-

〈Table 1〉 Summary Statistics of Likelihood to Purchase

\begin{tabular}{|l|l|c|c|c|}
\cline { 3 - 4 } \multicolumn{2}{c|}{} & \multicolumn{2}{c|}{ Likelihood to Purchase } & \multicolumn{1}{c|}{$\mathrm{n}$} \\
\hline \multirow{3}{*}{ Mood Group } & \multicolumn{1}{c|}{ CLOC } & Mean & Std. Deviation & 26 \\
\hline \multirow{4}{*}{ Nositive } & Internal $($ CLOC $\leq 3.09)$ & 4.192 & 1.833 & 25 \\
\cline { 2 - 5 } & External (CLOC $>3.09)$ & 3.960 & 1.881 & 51 \\
\cline { 2 - 5 } & Total & 4.078 & 1.842 & 26 \\
\hline & Internal (CLOC $\leq 3.64)$ & 5.269 & 1.663 & 26 \\
\cline { 2 - 5 } & External (CLOC $>3.64)$ & 2.538 & 1.067 & 52 \\
\cline { 2 - 5 } & Total & 3.904 & 1.953 & \\
\hline
\end{tabular}


split: Participants who scored below median score were considered to be internals, while participants who scored above median score were considered to be externals. From this table, it can be initially seen that in negative (vs. positive) mood condition, different CLOC tendencies influenced (vs. did not influence) likelihood to purchase. Figure 1 further illustrates the scatter plot between participants' likelihood to purchase and CLOC scores across two mood groups. Figure 1 shows the anticipated results: In negative mood condition, participants with lower CLOC scores (i.e. higher internal tendencies), showed higher likelihood to purchase than participants with higher CLOC scores (i.e. higher external tendencies). In positive mood condition, there was insignificant difference of likelihood to purchase among par- ticipants with different CLOC scores.

Table 2 presents several regression analyses (Echambadi and Hess 2007; Wang et al. 2012) to further validate the results of the experiment: (1) simple regression analyses for positive mood condition; (2) simple regression analyses for negative mood condition; and (3) multiple regression analysis with participants' likelihood to purchase as the dependent variable, while mean-centered CLOC scores, mood group conditions (coded $-1=$ positive mood; 1 $=$ negative mood), and their interactions as the independent variables. Simple regression analyses shows that in the positive mood condition, participants' likelihood to purchase was not influenced by their CLOC scores ( $B=$ -.091, $t=-.639, p>$.05). On the other hand, in negative mood condition, participants' like-

〈Figure 1〉 Scatter Plot of Likelihood to Purchase and CLOC

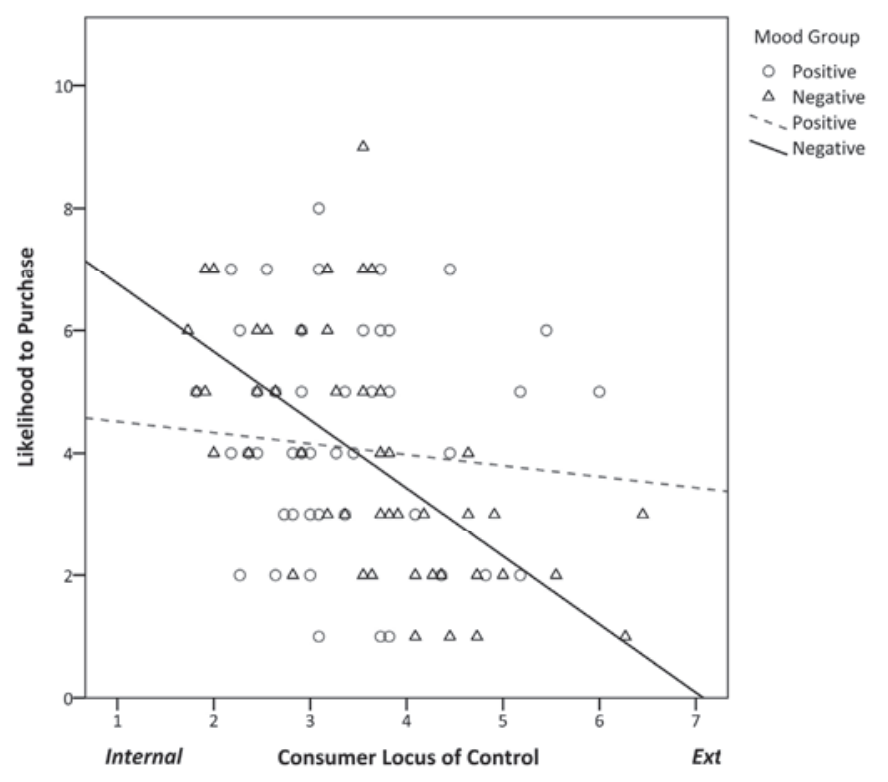

66 ASIA MARKETING JOURNAL Vol. 16 No. 02 July 2014 
〈Table 2〉 Regression Analyses Results

\begin{tabular}{|l|l|r|r|r|}
\hline \multicolumn{1}{|c|}{ Regression Model } & Variable & Beta & $t$ & Sig. \\
\hline Simple Regression for & (Constant) & & 15.615 & .000 \\
Positive Mood Group & CLOC & -.091 & -.639 & .526 \\
\hline Simple Regression for & (Constant) & & 18.378 & .000 \\
Negative Mood Group & CLOC & -.612 & -5.472 & .000 \\
\hline \multirow{3}{*}{ Multiple Regression for } & (Constant) & & 23.802 & .000 \\
Interaction Effect & Mood & -.021 & -.238 & .812 \\
& CLOC & -.343 & -3.776 & .000 \\
& Interaction & -.247 & -2.726 & .008 \\
\hline
\end{tabular}

lihood to purchase was negatively influenced V. Discussion by their CLOC scores $(B=-.612, t=-5.472$, $p<.001)$. More importantly, multiple $\mathrm{re}^{-}$ gressions analysis also further confirms a significant interaction between mood groups and CLOC $(B=-.247, t=-2.726, p<.01)$; therefore, CLOC moderates mood effects on likelihood to purchase (see Figure 2).

This paper examines how consumer locus of control (CLOC) could moderate mood effects on consumers' likelihood to purchase. Results of the experiment confirm the expected hypotheses: In the positive mood condition, CLOC tendencies did not influence participants' like-

〈Figure 2〉 Likelihood to Purchase as a Function of Mood and CLOC

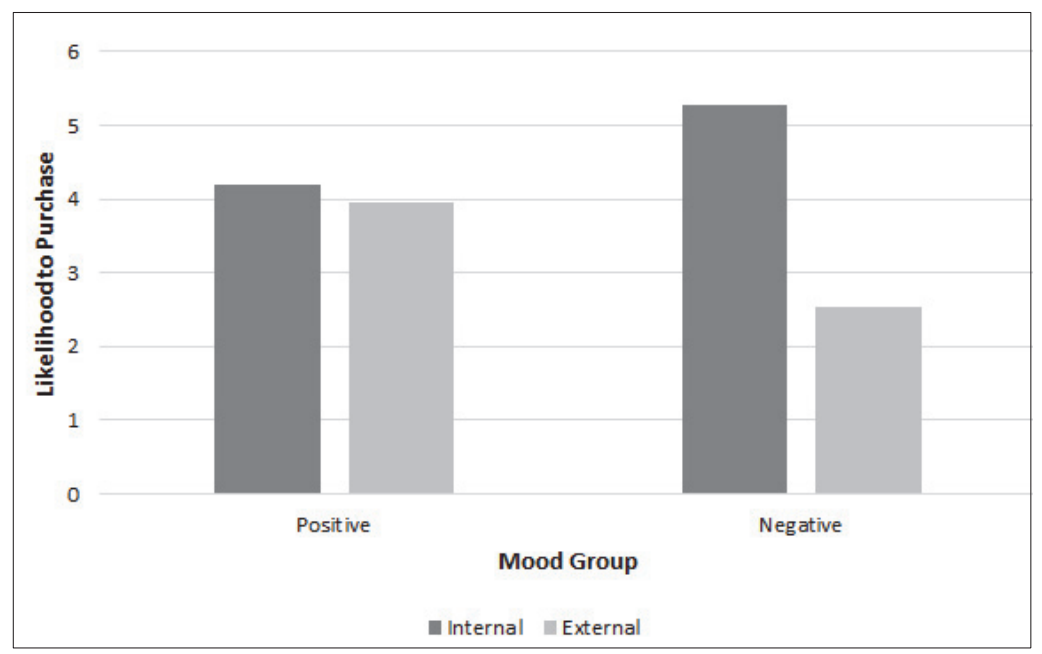

Consumer Locus of Control as a Moderator of the Relationship between Mood and Consumers' Likelihood to Purchase 67 
lihood to purchase (H1). In the negative mood condition, participants with higher internal (vs. external) CLOC tendencies showed a higher (vs. lower) likelihood to purchase (H2); this phenomenon implies that participants with higher internal CLOC tendencies tend to have higher tendencies to regulate their negative mood states. Thus, these findings demonstrate the central notion of this paper that CLOC acts as a moderator between mood effects and consumers' likelihood to purchase.

The data results also suggest that participants have quite high internal tendencies, as indicated by low CLOC scores $(M=3.5$; $S D$ $=1.004$ in a 9 -points scale). This condition may emerge because (1) people are assumed to have slight changes in LOC tendencies as they age or (2) cultural factor in South Korea. People are assumed to be more internal until the middle age (Gatz and Karel 1993; Schultz and Schultz 2004); however, other researchers still argue the rationality of this premise (Cobb-Clark and Schurer 2011; Lachman and Weaver 1998). Another factor that may influence this phenomenon is a cultural aspect: Korean students tend to view self-effort as the main factor contributing to success and failure (Park and Kim 2006). Furthermore, Park and Kim (1998) also suggested that Korean students usually have higher internal tendencies of LOC than Korean-Chinese and Chinese students.

\subsection{Theoretical Implications}

This research extends current literatures in four aspects. First, this paper tests the idea that consumers may or may not have the control to regulate their mood. The findings suggest that consumers who have higher internal (vs. external) CLOC tendencies show higher (vs. lower) likelihood to purchase. The occurrence of these effects implies that internal CLOC consumers would show mood regulation effect, and external CLOC consumers would show mood evaluation effect. Hence, consumers' CLOC would influence their motivation and tendencies to regulate their mood. This finding increases further understanding regarding the interplay between mood evaluation and mood regulation effects.

Second, this paper further validates that consumers' personal characteristics can moderate mood effects on consumer decision-making process and behavior (Andrade 2005; Puccinelli et al. 2007; Smith and Petty 1995). Specifically, this research identifies the moderating role of consumer locus of control (CLOC) in the relationship between mood and consumers' likelihood to purchase. Consumers with internal CLOC tendencies would show a high likelihood to purchase. However, consumers with external tendencies would show high (vs. low) likelihood to purchase when they experience the positive (vs. negative) mood.

Third, the results of this paper also comple- 
ment extant literatures concerning the role of mood on self-regulation. Consumers in the negative mood are showed to have higher tendencies to regulate their mood than consumers in positive mood. This condition could occur because negative mood itself is a clear indicator of a negative outcome; thus, consumers need to regulate their mood (Carver and Scheier 1998; Labroo and Rucker 2010). However, there is still no clear agreement regarding the role of positive mood in the self-regulation process (Fedorikhin and Patrick 2010).

Finally, this research offers additional evidence that the information and effects of mood can be processed by consumers through unconscious manner. Research of White and McFarland (2009) demonstrated that consumers who focus on their mood and be consciously alert of its effects would experience greater mood impacts on their judgment process. However, other researchers argue that although consumers may not be fully aware of the presence and effects of mood (Chartrand 2005; Luomala and Laaksonen 2000), mood can influence consumer judgment process and behavior. Based on the methods of this research (i.e. mood manipulation through video clips and music), the findings suggest that a mood could influence consumers through unconscious processing system.

\subsection{Practical Implications}

This present research also provides two prac- tical implications. First, firms should consider the mood states and CLOC tendencies of consumers when they put advertisements. Although some researchers consider that consumers' control tendencies are somehow constant, other researchers argue that a different control tendencies can be induced by evoking a sense of control on people (Fisher and Johnstion 1996; Ottley et al. 2012; Schultz and Schultz 2004). This paper shows that, in negative mood condition, internal CLOC consumers show a higher likelihood to purchase than external CLOC consumers. Thus, for example, in the setting of TV advertisements, firms could create an advertisement which evokes a sense of control during TV program which promotes negative mood (e.g., drama, tragedy).

Second, firms in retail or service business could use music background to induce a positive mood on consumers. Firms and marketers should be aware that not all positive atmospherics of the environment in retail or service settings are positively perceived by consumers (Puccinelli et al. 2007); thus, music background is one notable marketing tool. Ample research has established that music could influence consumers' affective states and their behavior in a strong and diverse ways (Alpert et al. 2005; Garlin and Owen 2006); moreover, music background can be easily adjusted at a low-cost (Demoulin 2011). Therefore, by inducing positive mood on consumers using music background, firms could positively influence consumer behavior regard- 
less consumers' CLOC tendencies.

\subsection{Limitations and Future Research}

Although effort was made to maximize the internal and external validity of the experiment, this research has several limitations that could be explored in the future research. First, although pre-test has confirmed that the advertisement is considered desirable, some participants suggested during the short-interview that they did not feel like having dessert at the time of the experiment (i.e. before lunch time) because dessert is generally consumed after meals; hence, future research could investigate how the type of product and the timing of an advertisement can influence consumers' likelihood to purchase. Second, the experiment has samples limited to Korean students; thus, it is important not to over-generalize the findings of this research. This limitation may also be the reason why the internal participants had unusually high CLOC scores $\left(M_{\text {internal }}=5.269\right.$ vs. $\left.M_{\text {external }}=2.538\right)$. Moreover, because cultural aspect can influence control tendencies (Park and Kim 2006; Park and Kim 1998), further studies could be conducted to examine the different effects of CLOC in different cultures to increase the robustness of the effects seen in this paper.

\section{Conclusion}

This paper explores how consumer locus of control could moderate mood effects on consumers' likelihood to purchase. The results are consistent with the predicted hypotheses: In negative mood condition, consumers with higher internal CLOC tendencies show a higher likelihood to purchase, while consumers with higher external CLOC tendencies show lower likelihood to purchase. In the positive mood, CLOC tendencies does not influence consumers' likelihood to purchase.

These findings extend the current literatures in four ways. First of all, the findings suggest that consumers with internal CLOC tendencies are more likely to regulate their negative mood than consumers with external CLOC tendencies. Second, CLOC tendencies could moderate mood effects on consumers' likelihood to purchase. Third, the results provide additional evidence concerning the role of negative mood in selfregulation. Finally, this paper also provides further evidence that mood could unconsciously influence consumer judgment process. This paper also offers managerial implications for firms and marketers. First, marketers should consider the mood states and CLOC tendencies of consumers in creating advertisements. Second, firms could aim to elicit positive mood on consumers so that their CLOC tendencies would not influence their positive responses toward 
products.

〈Received February 17. 2014〉

〈Revised April 24. 2014〉

〈Accepted July 9. 2014〉

\section{References}

Alpert, Mark I., Judy I. Alpert, and Elliot N. Maltz (2005), "Purchase Occasion Influence on the Role of Music in Advertising," Journal of Business Research, 58 (3), 36976.

Andrade, Eduardo B. (2005), "Behavioral Consequences of Affect: Combining Evaluative and Regulatory Mechanisms," Journal of Consumer Research, 32 (3), 355-62.

Arnold, Mark J. and Kristy E. Reynolds (2009), "Affect and Retail Shopping Behavior: Understanding the Role of Mood Regulation and Regulatory Focus," Journal of Retailing, 85 (3), 308-20.

Baas, Matthijs (2005), "Going Beyond Valence:

On the Induction of Discrete Moods and Emotions," University of Amsterdam.

Baumeister, Roy F. (1998), "The Self," in The Handbook of Social Psychology, Daniel T. Gilbert and Susah F. Fiske and Gardner Lindzey, eds. New York: Oxford University Press.

Bok, Sang Yong and Dongwon Min (2013), "The Effect of Emotional Certainty on
Attitudes in Advertising," Asia Marketing Journal, 14 (4), 57-75.

Bower, Gordon H. (1981), "Mood and Memory," American Psychologist, 36 (2), 129-48.

Busseri, Michael A., Herbert M. Lefcourt, and Robert R. Kerton (1998), "Locus of Control for Consumer Outcomes: Predicting Consumer Behavior," Journal of Applied Social Psychology, 28 (12), 1067-87.

Carver, Charles S. and Michael F. Scheier (1998), On the Self-Regulation of Behavior. New York: Cambridge University Press.

Chartrand, Tanya L. (2005), "The Role of Conscious Awareness in Consumer Behavior," Journal of Consumer Psychology, 15 (3), 203-10.

Cobb-Clark, Deborah A. and Stefanie Schurer (2011), "Two Economists' Musings on the Stability of Locus of Control," Institute for the Study of Labor (IZA) Discussion Paper No. 5630.

Cohen, Joel B. and Charles S. Areni (1991), "Affect and Consumer Behavior," in Handbook of Consumer Behavior, Thomas S. Robertson and Harold H. Kassarjian, eds. Englewood Cliffs, NJ: Prentice Hall.

Cohen, Joel B., Michel T. Pham, and Eduardo B. Andrade (2008), "The Nature and Role of Affect in Consumer Behavior," in Handbook of Consumer Psychology, Curtis P. Haugtvedt and Paul Herr and Frank Kardes, eds. Mahwah, NJ: Erlbaum. 
Demoulin, Nathalie (2011), "Music Congruency in a Service Setting: The Mediating Role of Emotional and Cognitive Responses," Journal of Retailing and Consumer Services, 18 (1), 10-18.

Di Muro, Fabrizio and Kyle B. Murray (2012), "An Arousal Regulation Explanation of Mood Effects on Consumer Choice," Journal of Consumer Research, 39 (3), 574-84.

Echambadi, Raj and James D. Hess (2007), "Mean-Centering Does Not Alleviate Collinearity Problems in Moderated Multiple Regression Models," Marketing Science, 26 (3), 438-45.

Fedorikhin, Alexander and Vanessa M. Patrick (2010), "Positive Mood and Resistance to Temptation: The Interfering Influence of Elevated Arousal," Journal of Consumer Research, 37 (4), 698-711.

Fisher, Keren and Marie Johnstion (1996), "Experimental Manipulation of Perceived Control and Its Effect on Disability," $P_{S y^{-}}$ chology and Health, 11 (5), 657-69.

Gangestad, Steven W. and Mark Snyder (2000), "Self-Monitoring: Appraisal and Reappraisal," Psychological Bulletin, 126 (4), 530-55.

Garg, Nitika, Brian Wansink, and J. Jeffrey Inman (2007), "The Influence of Incidental Affect on Consumers' Food Intake," Journal of Marketing, 71 (January), 194-206.

Garlin, Francine V. and Katherine Owen (2006), "Setting the Tone with the Tune: A Meta-Analytic Review of the Effects of
Background Music in Retail Settings," Journal of Business Research, 59 (6), 755-64.

Gatz, Margaret and Michele J. Karel (1993), "Individual Change in Perceived Control over 20 Years," International Journal of Behavioral Development, 16 (2), 305-22.

Gendolla, Guido H. E. (2000), "On the Impact of Mood on Behavior: An Integrative Theory and a Review," Review of general psychology, 4 (4), 378-408.

Higgins, E. Tory (1997), "Beyond Pleasure and Pain," American Psychologist, 52 (December), 1280-300.

Hwang, Insuk, Eugene J. S. Won, and Sookeun Byun (2012), "Music as a Magical Cue: An Exploratory Study of Background Music and Purchase Intentions in Tv Home Shopping Programs," Asia Marketing Journal, 14 (3), 103-18.

Kemp, Elyria and Steven W. Kopp (2011), "Emotion Regulation Consumption: When Feeling Better Is the Aim," Journal of Consumer Behaviour, 10 (1), 1-7.

Labroo, Aparna A. and Derek D. Rucker (2010), "The Orientation-Matching Hypothesis: An Emotion-Specificity Approach to Affect Regulation," Journal of Marketing Research, 47 (5), 955-66.

Lachman, Margie E. and Suzanne L. Weaver (1998), "The Sense of Control as a Moderator of Social Class Differences in Health and Well-Being," Journal of Personality and social Psychology, 74 (3), 763-73. 
Leipämaa-Leskinen, Hanna (2007), "Contradictions in Food Consumption," International Journal of Consumer Studies, 31 (6), 597-602.

Leotti, Lauren A., Sheena S. Iyengar, and Kevin N. Ochsner (2010), "Born to Choose: The Origins and Value of the Need for Control," Trends in Cognitive Sciences, 14 (10), 457-63.

Litoral (2013), "Ensalada De Frutas," (accessed September 23, 2013), [available at http: //www.ellitoralconcordia.com/?p=15033].

Luomala, Harri T., Rajesh Kumar, Verner Worm, and J. D. Singh (2004), "CrossCultural Differences in Mood-Regulation: An Empirical Comparison of Individualistic and Collectivistic Cultures," Journal of International Consumer Marketing, 16 (4), 39-62.

Luomala, Harri T. and Martti Laaksonen (2000), "Contributions from Mood Research," Psychology \& Marketing, 17 (3), 195-233.

Maier, Erik, Robert Wilken, Helmut Schneider, and Gülpınar Kelemci Schneider (2012), "In the Mood to Buy? Understanding the Interplay of Mood Regulation and Congruence in an International Context," Marketing Letters, 23 (4), 1005-18.

Meloy, Margaret G. (2000), "Mood-Driven Distortion of Product Information," Journal of Consumer Research, 27 (3), 345-59.

Morris, William N. and Nora P. Reilly (1987), "Toward the Self-Regulation of Mood:
Theory and Research," Motivation and Emotion, 11 (3), 215-49.

O'Connor, Daryl B., Fiona Jones, Mark Conner, Brian McMillan, and Eamonn Ferguson (2008), "Effects of Daily Hassles and Eating Style on Eating Behavior," Health Psychology, 27 (1), S20-S31.

Ottley, Alvitta, R. Jordan Crouser, Caroline Ziemkiewicz, and Remco Chang (2012), "Priming Locus of Control to Affect Performance," in IEEE Conference on Visual Analytics Science and Technology. Seattle: IEEE.

Park, Young Shin and Uichol Kim (2006), "Family, Parent-Child Relationship, and Academic Achievement in Korea," in Indigenous and Cultural Psychology, Uichol Kim and Kuo-Shu Yang and Kwang-Kuo Hwang, eds. New York: Springer. (1998), "Locus of Control, Attributional Style, and Academic Achievement: Comparative Analysis of Korean-Chinese, and Chinese Students," Asian Journal of Social Psychology, 1 (2), 191-208.

Puccinelli, Nancy M., Rohit Deshpande, and Alice M. Isen (2007), "Should I Stay or Should I Go? Mood Congruity, SelfMonitoring and Retail Context Preference," Journal of Business Research, 60 (6), 640-48.

Rusting, Cheryl L. (1998), "Personality, Mood, and Cognitive Processing of Emotional Information: Three Conceptual Frameworks," 
Psychological Bulletin, 124 (2), 165-96.

Schultz, Duane P. and Sydney Ellen Schultz (2004), Theories of Personality. Belmont, $\mathrm{CA}$ : Cengage Learning.

Schwarz, Norbert and Gerald L. Clore (1983), "Mood, Misattribution, and Judgments of Well-Being: Informative and Directive Functions of Affective States," Journal of Personality and Social Psychology, 45 (3), 513-23.

Seligman, Martin E. P. (1975), Helplessness:

On Depression, Development, and Death. San Francisco, CA: Freeman.

Siemer, Matthias (2001), "Mood-Specific Effects on Appraisal and Emotion Judgements," Cognition \& Emotion, 15 (4), 453-85.

Smith, Stephen M. and Richard E. Petty (1995), "Personality Moderators of Mood Congruency Effects on Cognition: The
Role of Self-Esteem and Negative Mood Regulation," Journal of Personality and Social Psychology, 68 (6), 1092-107.

Vohs, Kathleen D., Roy F. Baumeister, and George Loewenstein (2007), Do Emotions Help or Hurt Decision Making? A Hedgefoxian Perspective. New York: Russell Sage Foundation Publications.

Wang, Jing, Rui Juliet Zhu, and Baba Shiv (2012), "The Lonely Consumer: Loner or Conformer?," Journal of Consumer Research, 38 (6), 1116-28.

White, Katherine and Cathy McFarland (2009), "When Are Moods Most Likely to Influence Consumers' Product Preferences? The Role of Mood Focus and Perceived Relevance of Moods," Journal of Consumer Psychology, 19 (3), 526-36. 
〈Appendix〉 Fruit Dessert Advertisement

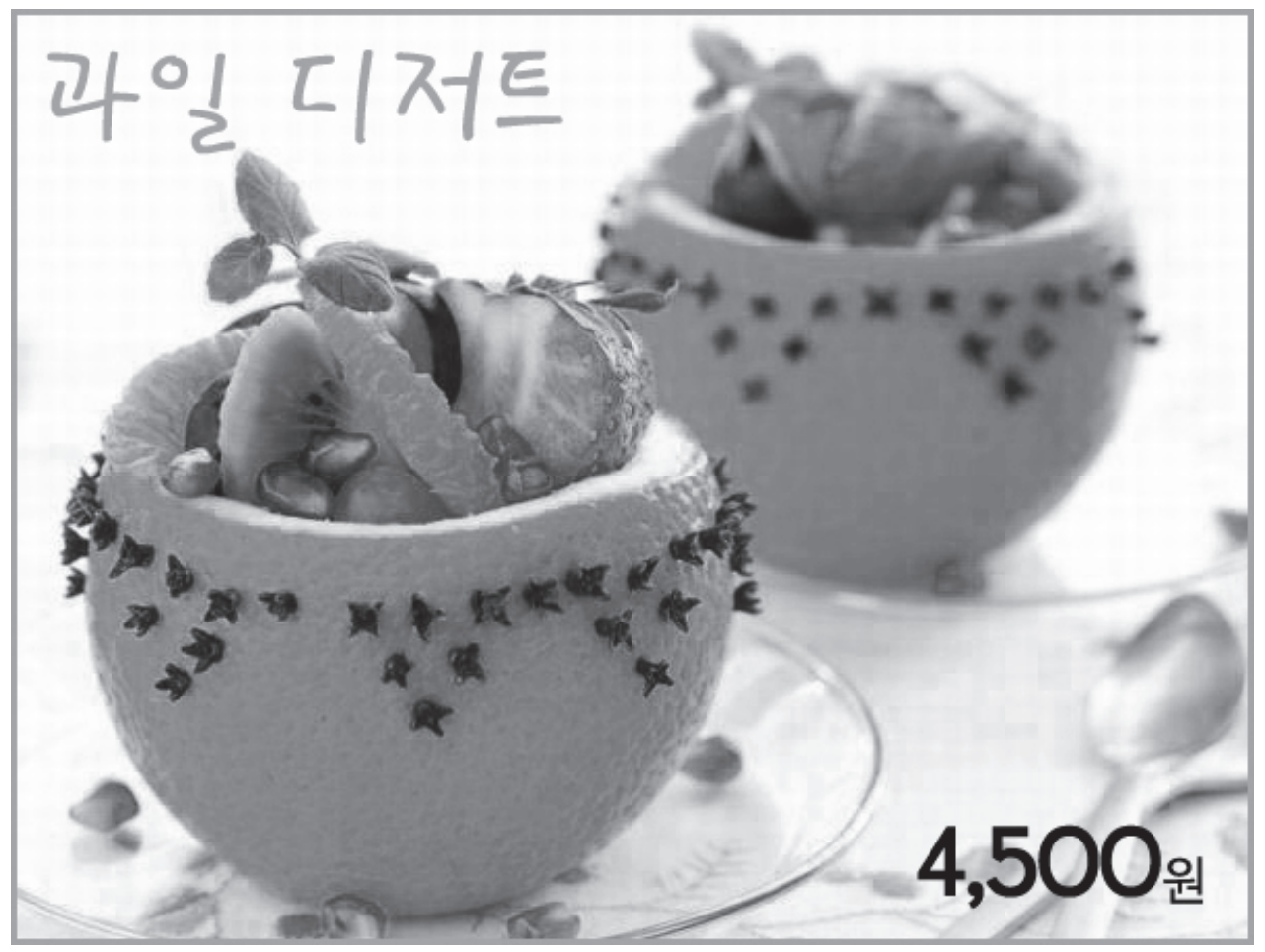

